\title{
The X-ray Photoabsorption Spectrum of Potassium near the K-edge
}

\author{
Y. Azuma", J. Suleiman", H.G. Berry, P.L. Cowan, D.S. Gemmell, T. LeBrun, \\ Physics Division, Argonne National Laboratory, Argonne, IL 60439
}

and

M. Westerlind

Department of Physics, University of Tennessee, Knoxville, TN 37996 and Oak Ridge National Laboratory, Oak Ridge, TN 37891

\begin{abstract}
We have used a heat-pipe target in an X-ray beam to obtain photoabsorption spectra of potassium at the K- and KM-edges, in the photon energy range 3600 to $3650 \mathrm{eV}$. Preliminary identifications of most of the peaks observed are made using Dirac Hartree-Fock calculations. We compare these results with those obtained previously in closed-shell rare gas absorption spectra.
\end{abstract}

PACS numbers:

Present address: KEK Photon Factory, 1-1, Oho, Tsukuba, Japan 305.

RECEIVED

“.Also at the Physics Department, University of Illinois, Chicago II 60680

FEB 281996

OSTI

[Final version will be double-spaced]

Notes for Yoshiro (and others): (1) Is there any Japanese work which should be referenced? (2)

All sections have been rewritten (3) still needs a few references

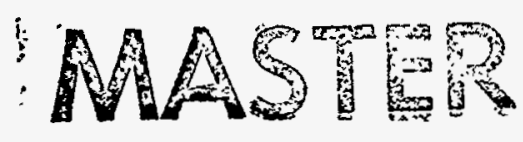

DISTRIPUTION OF THIS DOCUSAENT IS UNLMATED OH 


\section{DISCLAIMER}

Portions of this document may be illegible in electronic image products. Images are produced from the best available original document. 


\section{Introduction}

The photoabsorption spectra of rare gases were amongst the first measurements made when $\mathrm{x}$-ray light sources became available ${ }^{\mathbf{l}}$. Studies of the K-shell absorption edges in most of the rare gases have become possible with the advent of synchrotron radiation sources equipped with efficient X-ray crystal spectrometers ${ }^{2}$. Understanding of the absorption features at the K-edges has been a more gradual process. Many-electron processes are especially important in these studies where much of the time, more than one leectron is removed from the inner shells, with strong shakeup and shakeoff processes occurring. The many-electron processes provide strong tests of calculations of the electron correlation processes in many-electron atoms. Much work has been performed on the Argon K-edge region. The landmark paper of Breinig et al ${ }^{3}$ gave a careful interpretation of the complex features of several of these edges; most notably, for relevance to this work, their interpretation of the K-edge absorption features of argon. Deslattes et $\mathrm{al}^{4}$ have analyzed the multivacancy spectrum above the K-edge. Subsequently, higher-energy edges corresponding to double and triple inner-shell vacancy production, have also been observed in x-ray absorption spectra of some of the rare gases. The identification of the many configurations giving rise to these complex features is recent and still requires further theoretical and experimental.investigation. Many fewer studies of atomic open shell elements have been made, principally because of the generally lower densities possible in vapor targets, since most open shell atoms are solids or liquids at room temperatures. Some edges have been studied in the lighter alkalis; for example, lithium, by Ederer et al. ${ }^{6}$, and the sodium $\mathrm{K}$ edge, by Tuillier et al. $^{7}$

The $\mathrm{K}$ edge spectra of heavier atomic systems are strongly affected by relativistic effects: Crasemann et al ${ }^{8}$ have made several studies of the heavy rare gases to compare with calculations of edge energies, the Breit and other fine structure splittings. These measurements can lead to very precise tests of the many-body relativistic Hamiltonians used in the calculations. The coupling of open outer-shell electrons to the inner shell vacancies produced in these edges has not been studied in detail, either theoretically or experimentally.

In this paper we describe a first attempt to measure absorption spectra in potassium vapor. The heat-pipe technique described below should be applicable to measure X-ray absorption of most alkali vapors and other atoms and molecules which are not gaseous at normal room temperatures. We make identifications of resonances observed near the $\mathrm{K}$ threshold and the KM threshold in potassium, and compare these results with measurements made in argon by ourselves and other groups, and with calculations using a multi-configurational Dirac Hartree-Fock code.

\section{Experiment}

The experiment took place at the X-24A beamline of the X-ray ring at the Brookhaven National Synchrotron Light Source. The X-24A beamline, jointly operated by NIST(National Institute of Science and Technology) and Argonne, provides a well-focussed and monochromatized beam of photons in the energy range of 2 to $5 \mathrm{keV}$, and is equipped with a double-crystal monochromator with pre- and post-focussing mirrors ${ }^{9}$. The double crystal arrangement of the monochromator 
strongly reduces any second order harmonics. Silicon 111 crystals were used for these experiments. The photon beam was focussed to less than $1 \mathrm{~mm}^{2}$ spot size at the center of the absorption path.

Figure 1 is a schematic of the experimental arrangement. The apparatus consists of a half-meter long heat-pipe ${ }^{10}, 5 \mathrm{~cm}$ in diameter, with three-mil kapton windows. The tube is connected to a gas-handling system, and was filled with argon, typically to a pressure of 20 torr. The whole system was pumped out initially to better than $2 \times 10^{-7}$ torr. Pressure and vacuum gauges with electronic readouts allowed us to monitor the pressure to less than $1 \%$ at all pressures, and record the pressure simultaneous to each photoabsorption measurement. The center of the heat-pipe is surrounded by a heating coil encased in thermal insulating material. Water-cooling coils at each end of the pipe help to define a sharp cut off of the hot vapor section and prevent the vapor from reaching the end-windows. The output of a temperature sensor inside the heat-pipe acts as a thermostat to control the heater current and maintain a fixed temperature inside the heat-pipe. Heat-pipe conditions are obtained when the temperature at the center of the heat-pipe is such that the vapor pressure of the potassium (or other vaporizing material) is close to that of the buffer gas within the entire system. A "wick", typically a cylindrical metal gauze fitting close to the inside wall of pipe provides a returning path for vapor condensing at the ends of a stabilized center column of potassium vapor. When heat-pipe action ${ }^{11}$ is attained the vapor pressure of this central column of potassium is balanced by the buffer gas pressure on the outside, preventing any potassium vapor reaching the windows. In practice, the condition is realized from the increase in the reading of the gas pressure in the tube, which matches the expected potassium vapor pressure at the observed temperature setting in the middle of the tube.

The approach to equilibrium of the heat-pipe is made slowly to allow heat-pipe action to commence; otherwise, the return flow is not sufficient to prevent potassium, or other hot vapor, from escaping the tube and depositing on or disintegrating the heat-pipe end-windows. A second problem for absorption measurements is the maintenance of a constant absorption path. A thermostatic system based on an on/off current device can cause cycling in temperature, and thus in the absorption path-length. A preferable technique found was to maintain the equilibrium temperature with a constant heater current system.

A neon-filled ionization chamber was used to record the photon flux before the absorption tube, and a PIN diode monitored the flux following the absorption tube. The ratio of these two signals provide the raw absorption data. The attenuation observed includes that of the two kapton windows. Kapton has a monotonically decreasing absorption index with increasing energy in the regions near the $\mathrm{K}$ edges of potassium and argon. Four-jaw slits just in front of the ionization chamber defined the photon beam size to be less than $2 \mathrm{~mm}$ diameter within the chamber. The effective area of the PIN diode is about $1 \mathrm{~cm}^{2}$, and its position could be adjusted vertically and horizontally so that the $2 \mathrm{~mm} \times 2 \mathrm{~mm}$ beam was in the center of the PIN signal plateau region.

A second experiment to study the $\mathrm{K}$-edge, and the doubly excited $\mathrm{KL}$ and $\mathrm{KM}$ edges in argon was undertaken to allow an accurate comparison between argon and potassium. In this experiment the heat-pipe was replaced by a $10 \mathrm{~cm}$ long tube filled with argon to a pressure of 
about 10 torr. In other respects the two experiments were basically the same.

The potassium experiment consisted of making wavelength scans over the energy range of 3590 to $3670 \mathrm{eV}$ in steps of about $0.2 \mathrm{eV}$. Each scan took approximately 30 minutes, and groups of up to 20 scans were made sequentially. Instabilities in the heat pipe occasionally produced small vapor pressure bursts (typically an abrupt few percent effective path length change). Such scans which were eliminated during final data analysis.

\section{Results}

Figure 2 shows overview spectra of the argon and potassium $\mathrm{K}$ edge regions. The most noticeable feature is the $4 p$ resonance which is much stronger in the potassium spectrum. The ratio of $4 p$ resonance intensity to background is approximately 2.4 for potassium and only 1.2 for argon. The potassium ratio should be affected more by the instrumental width which was close to $0.8 \mathrm{eV}$, compared with about $0.6 \mathrm{eV}$ in the argon case. The relative strength of this resonance appears to be close to that observed by Esteva et $\mathrm{al}^{12}$ for the $3 \mathrm{p}$ resonance in neon This resonance is also enhanced in the corresponding alkali (sodium) spectrum of Tuillier et $\mathrm{al}^{7}$. The observed sodium and neon ratios are approximately 3.5 and 2.5 respectively. The enhancement could be due to mixing between the [1s]4s4p and the $4 p$ singly-excited state: however, our relativistic Hartree Fock calculations indicate almost no mixing in potassium. We suggest that the enhancement of the $4 p$ resonance arises due to the larger number of states in the final configuration. The coupling of the outer shell electron leads to more states in the final configuration, and to six instead of two transitions. An averaging over the individual oscillator strengths then suggests an increase of close to 2, as observed. A more systematic investigation of heavier alkalis and alkaline earth $\mathrm{K}$ edge spectra will help to verify this suggestion.

We have used the GRASP-II multi-configurational relativistic Hartree-Fock code $^{13}$ to calculate the transition energies and transition rates to fit the measured potassium $\mathrm{K}$ edge resonances. The calculation, which includes the ground state configuration and 15 excited state configurations, leads to the 46 transitions shown in the "stick spectrum" in the upper part of Fig. 3. The heights of the lines represent our calculated transition rates. By folding in an experimental halfwidth of $0.8 \mathrm{eV}$, and adding an arctangent function to represent the ionization limit, we are able to reproduce well the shape of the edge observed by experiment. The results of the calculation are shown in the center section of Fig. 3, and should be compared with the fitted potassium experimental curve shown in the bottom section of Fig. 3. The ionization limit and upper rydberg states are represented in the fit by an arctangent as shown in the lowest section of Fig. 3 . The strengths but not the positions of the resonance peaks are sensitive to the midpoint energy and the width of the arctangent function. The fit shown in Fig. 3 is obtained with a midpoint energy of $\mathrm{E}_{\mathrm{M}}=3914.5 \mathrm{eV}$, and a "halfwidth" $\mathrm{D}$ of $1.2 \mathrm{eV}$, where $\mathrm{E}_{\mathrm{M}}$ and $\mathrm{D}$ are defined in the function as arctangent $\left\{\left(E-E_{M}\right) / D\right\}$.

The absolute energy calibration of the potassium $4 p$ resonance was performed by measuring the energies of the known $L_{1}, L_{2}$ and $L_{3}$ edges of silver ${ }^{14}$, and the $K$ edge of argon. These measurements result in a value for the [1s] $4 s 4 \mathrm{p}$ resonance at $3609.94 \pm 1.0 \mathrm{eV}$. The [1s] $4 \mathrm{~s} 4 \mathrm{p}$ 
resonance is a sum of six transitions. The result is in reasonable agreement with previously tabulated values ${ }^{14}$. The weighted average over these transitions of our calculations leads to a theoretical value for the observed resonance of $3610.33 \mathrm{eV}$. The calculation includes a correction of about $4.0 \mathrm{eV}$ from Breit and quantum electrodynamic (QED) effects. Thus the measurement is quite sensitive to these relativistic terms. The agreement between theory and experiment (the difference is $0.39 \pm 1.0 \mathrm{eV}$ ) is approximately the expected precision of the calculations.

The other strong peaks arise mainly from transitions to the [1s]4s5p, the [1s]4p5s and the [1s]5s5p upper states. The [1s]3d4p and [1s]3d5p states lie close to the [1s]4s5p states but the transition rates to these states are much lower. We list some identifications and energies of the relevant transitions in Table I. We include only those transitions with the transition probabilities greater than $1.2 .10^{10} \mathrm{~s}^{-1}$. Most of the final states are strongly mixed in the LS configurations given, and we have included the principal wavefunctions for each upper state. The experimental energies given in the fifth column of Table I show good agreement with the centroids of the theoretical values after adjustment for the difference in experiment and theory for the $4 p$ resonance energy.

The KM doubly-excited satellites are also seen in both the argon and potassium spectra. Figure 4 shows an enhancement of these spectral regions. The identifications in the argon spectrum are taken from the work of Dyall et $\mathrm{al}^{15}$ who used a multi-configurational Hartree-Fock code, plus an extended shake theory to estimate the relative intensities. We have verified many of their identifications in this spectrum, and further detailed analysis is underway, benefitting from our improved signal to noise ratio and resolution for this argon spectrum. Our preliminary identifications in the potassium $\mathrm{KM}$ spectrum are indicated in the lower half of Fig. 4 . The multiconfigurational Dirac-Fock calculations included up to 250 excited configurations. We derived energies and transition rates for all the [1s3p]4snp ${ }^{2}$ levels, where $n=4,5,6$, and 7 . This resulted in 188 allowed transitions from the ground state by single photon excitation. The strongest 20 transitions, taken within each $\mathrm{np}^{2}$ manifold are listed in table II.

The first three peaks of the strong quartet of peaks in the KM potassium spectrum of Fig. 4 arise from transitions to the [1s3p] $4 s 4 p^{2}$ configuration. None of the calculated transitions can account for the fourth peak of this quartet. The next doublet can be assigned to transitions to the [1s3p] $4 s 5 p^{2}$ configuration. It is likely that transitions to the [1s3p]4s4p5p overlap with this latter transition. Unfortunately, this involves a configuration with five open shells which are too many to be accommodated with the present code. The calculations cannot be considered complete until several of these configurations with five-open shells have been included. We suggest that the fourth peak of the strong quartet of lines belongs to these [1s3p]4s4p5p and [1s3p]4s4p3d configurations. Its experimental energy is at $3642.4 \mathrm{eV}$. The [1s3p] $4 \mathrm{~s}$ limit is indicated above the $[1 \mathrm{~s} 3 \mathrm{p}] 4 \mathrm{~s} 7 \mathrm{p}^{2}$ position at an energy of $3655 \mathrm{eV}$. This limit includes four $[1 \mathrm{~s} 3 \mathrm{p}]^{3} \mathrm{P} 4 \mathrm{~s}^{4} \mathrm{P}$ and ${ }^{2} \mathrm{P}$ levels, the lowest of which is calculated to be the ${ }^{4} \mathrm{P}_{5 / 2}$ level at $3654.41 \mathrm{eV}$, and two [1s3p] ${ }^{1} \mathrm{P}$ $4 s^{2} P_{1 / 2,3 / 2}$ levels calculated to lie at $3655.9 \mathrm{eV}$. The energy range between $3645 \mathrm{eV}$ and $3655 \mathrm{eV}$ must contain many transitions to other levels with 5 open shells of the general type [1s3p]4s4pnl, [1s3p]4s5pnl, etc. Above this limit, we observe, but have not classified, peaks due to transitions 
to configurations of the type [1s3s]n $/ n^{\prime} l$.

\section{Conclusion}

We have measured the $\mathrm{K}$ and $\mathrm{KM}$ edge absorption spectra in potassium for the first time. We note that the $4 \mathrm{p}$ resonance is stronger relative to the ionization continuum in potassium than in the neighboring argon nobel gas spectrum. The same enhancement appears in the respective sodium and neon spectra. We have made identifications of many of the observed structures using GRASP-II, a multi-configurational relativistic Hartree Fock code. The measured energies are accurate to $\pm 0.1 \mathrm{eV}$. The theoretical values of the singly excited core-hole states appears accurate to $\pm 0.5 \mathrm{eV}$, and the double-hole states have an accuracy of $\pm 2 \mathrm{eV}$. Our work shows the need to incorporate five open shell systems in this code in order to treat double inner-shell vacancy promotions in already open shell atoms. Within these limitations the calculations show reasonable agreement with the measurements for the $\mathrm{K}$ and the $\mathrm{KM}$ edges giving confidence in these preliminary identifications.

\section{Acknowledgements}

We thank Barry Karlin for his assistance with the experiment at the X-24A beam line,. This work was supported by the U.S. Department of Energy, Office of Basic Energy Sciences, under Contract No. W-31-109-ENG-38. 


\section{References}

1. See, for example, A.E. Sandström, Experimental Methods of X-ray Spectroscopy, Handbuch der Physik, pp. 78-245, vol 30; ed. by S. Flügge (Springer Verlag.

Berlin, 1957)

2. first X-ray spectros

3. M. Breinig, M.H. Chen, G.E. Ice, F. Parente, B. Crasemann and G.S. Brown, Phys. Rev. A22, 520 (1980) - see other references in this work and in ref. 4 below.

4. R.D. Deslattes, R.E. LaVilla, P.L. Cowan, and A, Henins, Phys. Rev. A27, 923 (1983)

5. M. Deutsch and M. Hart, Phys. Rev. A29, 2946 (1984); U. Kuetgens and J. Hormes, Phys. Rev. A44, 264 (1991)

6. D. Ederer...

7. M.H. Tuillier, D. Laporte and J. Esteva, Phys. Rev. A26, 372 (1983)

8. See, for example, S.J. Schaphorst, A.F. Kodre, J. Ruscheinski, B. Crasemann, T. Aberg, J. Tulkki, M.H. Chen, Y. Azuma and G.S. Brown, Phys. Rev. (1993)

9. X24A description

10. Heatpipe model HP-801, Comstock Inc, Oak Ridge, TN

11. C.R. Vidal and J. Coper, J. Appl. Phys. 40, 3370 (1969)

12. J.M. Esteva, B. Gauthé, P. Dhez and R.C. Karnatak, J. Phys. B16, L263 (1983)

13. N.C.Pyper, I.P.Grant and N. Beatham, Comp. Phys. Comm. 15, 387 (1978); we thank Farid Parpia for use of the most recent code version, GRASP II, as used in this work. See also F. Parpia and C. Froese-Fischer, $\mathbf{x x x x}$

14. B. Nordfors, Ark, f. Fys. 19, 259 (1961); ibid, 20, 25 (1962)

15. K.G. Dyall and I.P. Grant, J. Phys. B 17, 1281 (1984); K.G. Dyall and R.E. LaVilla, Phys. Rev. A34, 5123 (1986) 
Table II. Transition energies and transition rates for $\mathrm{KM}$-double excitation in potassium to the $[1 s 3 p] 4 s 4 p^{2}, 5 p^{2}, 6 p^{2}, 7 p^{2}$ levels - for the strongest transitions only. The experimental errors are given relative to the $4 p$ resonance energy.

Excited state configuration

$[1 \mathrm{~s} 3 \mathrm{p}]^{3} \mathrm{P} 4 \mathrm{~s}^{2} \mathrm{P} 4 \mathrm{p}^{2}{ }^{3} \mathrm{P}_{2}{ }^{2} \mathrm{P}_{1 / 2}$ $[1 \mathrm{~s} 3 \mathrm{p}]^{3} \mathrm{P} 4 \mathrm{~s}^{2} \mathrm{P} 4 \mathrm{p}^{2}{ }^{3} \mathrm{P}_{2}{ }^{2} \mathrm{~S}_{1 / 2}$ [ls $3 p]^{3} \mathrm{P} 4 \mathrm{~s}^{2} \mathrm{P} 4 \mathrm{p}^{2}{ }^{3} \mathrm{P}_{2}{ }^{2} \mathrm{P}_{3 / 2}$ [1s3p] ${ }^{3} \mathrm{P} 4 \mathrm{~s}^{4} \mathrm{P} 4 \mathrm{p}^{2}{ }^{1} \mathrm{~S}_{0}{ }^{4} \mathrm{P}_{1 / 2}$ [ls $\mathrm{p}]^{1} \mathrm{P} 4 \mathrm{~s}^{2} \mathrm{P} 4 \mathrm{p}^{2}{ }^{1} \mathrm{D}_{2}{ }^{2} \mathrm{P}_{1 / 2}$ [1s3p] ${ }^{1} \mathrm{P} 4 \mathrm{~s}^{2} \mathrm{P} 4 \mathrm{p}^{2}{ }^{1} \mathrm{D}_{2}{ }^{2} \mathrm{P}_{3 / 2}$ $[1 \mathrm{~s} 3 \mathrm{p}]^{3} \mathrm{P} 4 \mathrm{~s}^{4} \mathrm{P} 4 \mathrm{p}^{2}{ }^{3} \mathrm{P}_{2}{ }^{2} \mathrm{P}_{3 / 2}$ [1s3p] ${ }^{1} \mathrm{P} 4 \mathrm{~s}^{2} \mathrm{P} 4 \mathrm{p}^{2}{ }^{1} \mathrm{~S}_{0}{ }^{2} \mathrm{P}_{3 / 2}$ [1s3p] ${ }^{3} \mathrm{P} 4 \mathrm{~s}^{4} \mathrm{P} 4 \mathrm{p}^{2}{ }^{3} \mathrm{P}_{2}{ }^{2} \mathrm{P}_{1 / 2}$ [1s $3 \mathrm{p}]^{3} \mathrm{P} 4 \mathrm{~s}^{2} \mathrm{P} 4 \mathrm{p}^{2}{ }^{3} \mathrm{p}_{2}{ }^{2} \mathrm{P}_{1 / 2}$ $[1 \mathrm{~s} 3 \mathrm{p}]^{3} \mathrm{P} 4 \mathrm{~s}^{2} \mathrm{P} 4 \mathrm{p}^{2}{ }^{3} \mathrm{P}_{2}{ }^{2} \mathrm{P}_{3 / 2}$

[ls3p]4s4p5p

[1s3p]4s4p3d

$[1 \mathrm{~s} 3 \mathrm{p}]]^{3} \mathrm{P} 4 \mathrm{~s}^{4} \mathrm{P} 5 \mathrm{p}^{2}{ }^{3} \mathrm{P}_{2}{ }^{2} \mathrm{P}_{3 / 2}$ $[1 \mathrm{~s} 3 \mathrm{p}]^{3} \mathrm{P} 4 \mathrm{~s}^{4} \mathrm{P} 5 \mathrm{p}^{2}{ }^{3} \mathrm{P}_{2}{ }^{2} \mathrm{P}_{1 / 2}$ [1s $3 p]^{3} \mathrm{P} 4 \mathrm{~s}^{2} \mathrm{P} 5 \mathrm{p}^{2}{ }^{3} \mathrm{P}_{2}{ }^{2} \mathrm{P}_{1 / 2}$ [1s3p] $\mathrm{P} 4 \mathrm{~s}^{2} \mathrm{P} 5 \mathrm{p}^{2}{ }^{1} \mathrm{D}_{2}{ }^{2} \mathrm{P}_{3 / 2}$ $[1 \mathrm{~s} 3 \mathrm{p}]^{\mathrm{l}} \mathrm{P} 4 \mathrm{~s}^{2} \mathrm{P} 5 \mathrm{p}^{2}{ }^{1} \mathrm{D}_{2}{ }^{2} \mathrm{P}_{1 / 2}$

[1s3p] $]^{3} \mathrm{P} 4 \mathrm{~s}^{4} \mathrm{P} 6 \mathrm{p}^{2}{ }^{3} \mathrm{P}_{2}{ }^{2} \mathrm{P}_{3 / 2}$ [1s3p] $]^{3} \mathrm{P} 4 \mathrm{~s}^{4} \mathrm{P} 6 \mathrm{p}^{2}{ }^{3} \mathrm{P}_{2}{ }^{6} \mathrm{D}_{3 / 2}$ $[1 \mathrm{~s} 3 \mathrm{p}]^{3} \mathrm{P} 4 \mathrm{~s}^{4} \mathrm{P} 6 \mathrm{p}^{2}{ }^{3} \mathrm{p}_{2}{ }^{4} \mathrm{D}_{1 / 2}$ $[1 s 3 p]^{3} \mathrm{P} 4 \mathrm{~s}^{4} \mathrm{P} 6 \mathrm{p}^{2}{ }^{1} \mathrm{D}_{2}{ }^{4} \mathrm{D}_{1 / 2}$

$[1 \mathrm{~s} 3 \mathrm{p}]^{3} \mathrm{P} 4 \mathrm{~s}^{4} \mathrm{P} 7 \mathrm{p}^{2}{ }^{3} \mathrm{P}_{2}{ }^{2} \mathrm{P}_{3 / 2}$ $[1 \mathrm{~s} 3 \mathrm{p}]^{3} \mathrm{P} 4 \mathrm{~s}^{4} \mathrm{P} 7 \mathrm{p}^{2}{ }^{3} \mathrm{P}_{2}{ }^{2} \mathrm{P}_{1 / 2}$ $[1 \mathrm{~s} 3 \mathrm{p}]^{1} \mathrm{P} 4 \mathrm{~s}^{2} \mathrm{P} 6 \mathrm{p}^{2}{ }^{1} \mathrm{D}_{2}{ }^{2} \mathrm{P}_{3 / 2}$ $[1 \mathrm{~s} 3 \mathrm{p}]^{1} \mathrm{P} 4 \mathrm{~s}^{2} \mathrm{P} 6 \mathrm{p}^{2}{ }^{1} \mathrm{D}_{2}{ }^{2} \mathrm{P}_{1 / 2}$ [1s $3 \mathrm{p}]^{3} \mathrm{P} 4 \mathrm{~s}^{4} \mathrm{P} 7 \mathrm{p}^{2}{ }^{3} \mathrm{P}_{2}{ }^{2} \mathrm{P}_{1 / 2}$ [1s3p] $]^{1} \mathrm{P} 4 \mathrm{~s}^{2} \mathrm{P} 7 \mathrm{p}^{2}{ }^{1} \mathrm{D}_{2}{ }^{2} \mathrm{P}_{3 / 2}$ [1s3p] ${ }^{1} \mathrm{P} 4 \mathrm{~s}^{2} \mathrm{P} 7 \mathrm{p}^{2}{ }^{1} \mathrm{D}_{2}{ }^{2} \mathrm{P}_{1 / 2}$ [ls $3 \mathrm{p}]^{1} \mathrm{P} 4 \mathrm{~s}^{2} \mathrm{P} 7 \mathrm{p}^{2}{ }^{1} \mathrm{D}_{2}{ }^{2} \mathrm{D}_{3 / 2}$

[ls3p]4s Ion limit

\begin{tabular}{|c|c|c|}
\hline Transition energy & Transit & erimental Energ \\
\hline $\mathrm{eV}$ & $10^{4} \mathrm{~s}^{-1}$ & $\mathrm{eV}$ \\
\hline 3638.336 & 99278 & $3636.05 \pm 0.20$ \\
\hline 3638.436 & 69474 & \\
\hline 3638.473 & 147808 & \\
\hline 3640.683 & 23228 & $\cdot$ \\
\hline 3640.761 & 76844 & $3638.48 \pm 0.20$ \\
\hline 3640.792 & 90111 & \\
\hline 3641.748 & 59334 & \\
\hline 3641.899 & 59519 & \\
\hline 3641.986 & 108316 & $3640.21 \pm 0.20$ \\
\hline 3642.696 & 33867 & \\
\hline 3642.782 & 37803 & \\
\hline- & & $3642.32 \pm 0.20$ \\
\hline 3646.826 & 66.4 & \\
\hline 3646.878 & 115.6 & $3646.25 \pm 0.20$ \\
\hline 3646.894 & 69.50 & \\
\hline 3648.239 & 192.3 & \\
\hline 3648.267 & 205.1 & $3649.0 \pm 0.2$ \\
\hline 3649.259 & 7.24 & \\
\hline 3649.373 & 5.27 & \\
\hline 3649.414 & 5.31 & \\
\hline 3649.574 & 8.90 & \\
\hline 3650.576 & 2.49 & \\
\hline 3650.738 & 2.01 & \\
\hline 3650.823 & 13.1 & \\
\hline 3650.853 & 18.03 & \\
\hline 3650.884 & 2.26 & \\
\hline 3652.107 & 2.63 & \\
\hline 3651.140 & 4.17 & \\
\hline 3652.147 & 1.52 & \\
\hline
\end{tabular}

$3655.5 \pm 0.3$ 


\title{
Figure Captions
}

Figure 1. The experimental arrangement for absorption measurements at the NSLS X-24A beamline. The heat pipe was replaced by a short cell of argon gas for the argon absorption measurements.

Figure 2. Spectra of the K-shell absorption edges in argon (upper) and potassium (lower). The spectra show the strong $4 p$ resonances at the edge plus multivacancy excitation at higher energies.

Figure 3. Calculated transitions in potassium. The (upper) stick spectra have heights proportional to the Einstein A-values for the 46 transitions. Note scale change of the dominating $4 \mathrm{p}$ transition. The middle spectrum shows the result after folding in an experimental halfwidth of $0.8 \mathrm{eV}$, and an arctangent function for the ionization edge at $3615.5 \mathrm{eV}$. The lowest spectum shows a fit to the experimental spectrum.

Figure 4. Comparisons of the KM satellite structures in argon and potassium. Theoretical identifications are given.

\section{DISCLAIMER}

\begin{abstract}
This report was prepared as an account of work sponsored by an agency of the United States Government. Neither the United States Government nor any agency thereof, nor any of their employees, makes any warranty, express or implied, or assumes any legal liability or responsibility for the accuracy, completeness, or usefulness of any information, apparatus, product, or process disclosed, or represents that its use would not infringe privately owned rights. Reference herein to any specific commercial product, process, or service by trade name, trademark, manufacturer, or otherwise does not necessarily constitute or imply its endorsement, recommendation, or favoring by the United States Government or any agency thereof. The views and opinions of authors expressed herein do not necessarily state or reflect those of the United States Government or any agency thereof.
\end{abstract}




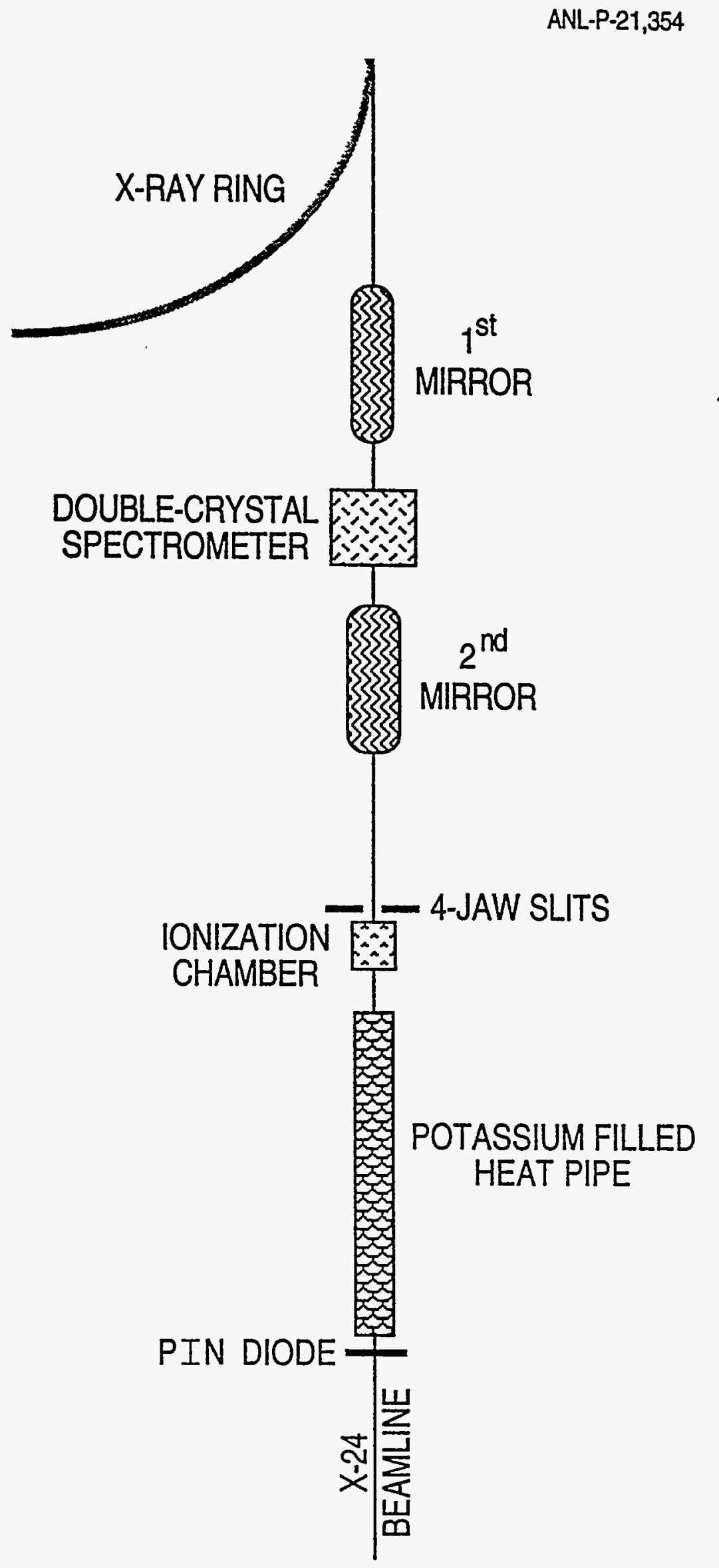




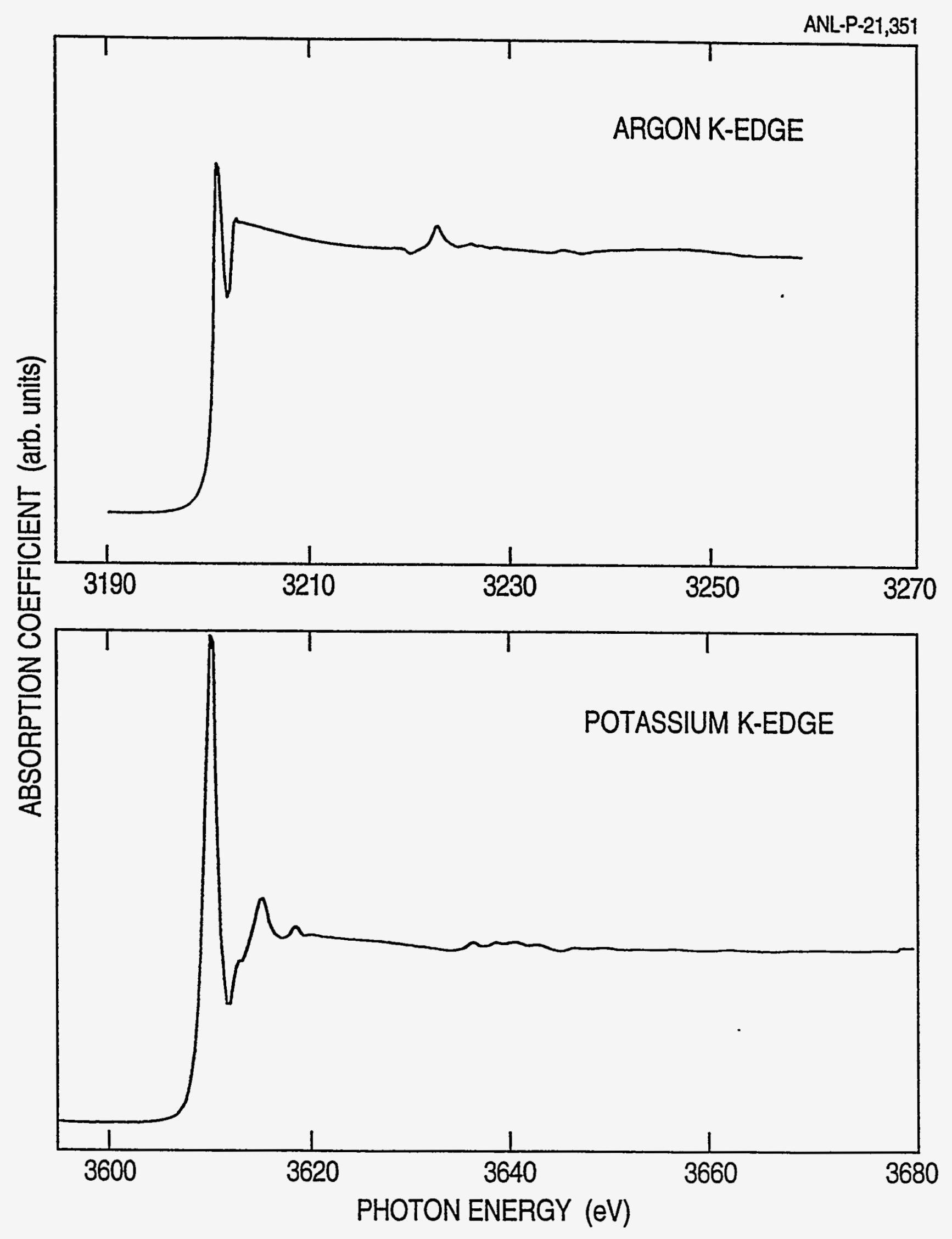




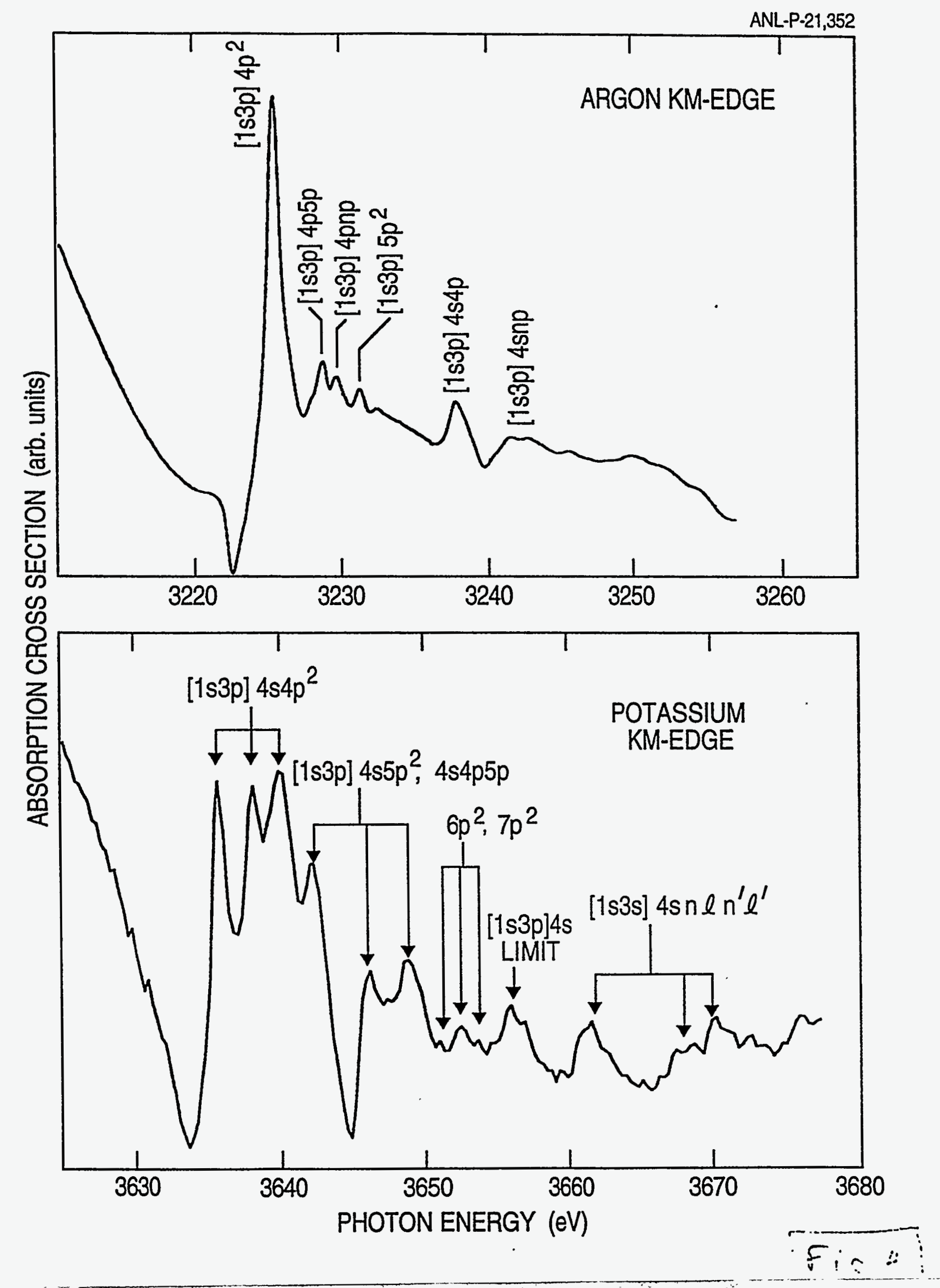

